\title{
Planejamento urbano-turístico em Fortaleza: perspectivas pós-Copa 2014
}

\section{The urban-tourism plan in Fortaleza: perspectives after Cup 2014}

Alexandre Queiroz Pereira - Universidade Federal do Ceará, Centro de Ciências, Departamento de Geografia. Doutorado e Mestrado em Geografia. E-mail: aqpufc@ gmail.com

Enos Feitosa de Araújo - Instituto Federal de Educação, Ciência e Tecnologia do Ceará, Campus Aracati. Doutorando em Geografia. Mestrado em Geografia. E-mail: enosfeitosa@gmail.com

Bruno Rodrigues da Silveira - Instituto Federal de Educação, Ciência e Tecnologia Baiano, Curso de Geografia - Campus Santa Inês. Doutorando em Geografia. Mestrado em Geografia. E-mail: brunosilveira1985@gmail.com

\section{Resumo}

Nas três últimas décadas, o turismo apresenta-se como uma importante atividade econômica no estado do Ceará, privilegiado por várias políticas públicas estaduais e federais. Nesse contexto, a atividade torna-se justificativa para o desenvolvimento de planejamento urbanoturístico objetivando o desenvolvimento econômico do estado. Neste ensaio, a cidade de Fortaleza apresenta-se como o locus desse modelo de planejamento, que, com a influência temporal da Copa do Mundo de 2014, passa por novas estratégias socioespaciais com o objetivo de contruir ainda mais os fixos e consolidar os fluxos turísticos.

\section{Palavras-chave}

Turismo. Planejamento Urbano. Copa do Mundo.

\begin{abstract}
Over the past three decades, tourism has been recognised as an important economic growth factor of the state of Ceará, helped by several state and federal public policy in Brazil. In such a context, the tourism joins with the logic of urban-tourism planning in order to promote the economic development of the State of Ceará. This essay presents the city of Fortaleza as the locus of this urban-tourism planning of Ceará with the influence of the 2014 FIFA World Cup which aims to further consolidate tourist flows. Within this scenario, we discuss the current context of tourism on the new strategies and perspectives of the after 2014 FIFA World Cup in Fortaleza.
\end{abstract}

\section{Keywords}

Tourism, Urban Planning, FIFA World Cup. 


\section{INTRODUÇÃO}

A imagem do Ceará moderno é elaborada, sobremaneira, pela promoção da turistificação da cidade de Fortaleza, especificamente associada às práticas desenvolvidas na sua orla marítima (DANTAS et al., 2008). Processo iniciado mais incisivamente na década de 1990, a organização da atividade turística no Ceará tem como condição importante o convencimento da sociedade local acerca da vocação turística do estado, notadamente a face litorânea da metrópole. Para tanto, o principal argumento do governo estadual está relacionado aos desdobramentos econômicos da atividade, em destaque o aumento das taxas de emprego e a elevação da renda da população. Tal estratégia é relevante para consolidar politicamente um projeto que nasce dos gestores/planejadores e carece da alocação de significativo volume de recursos públicos.

No ano de 2009, com a divulgação da inclusão da cidade de Fortaleza como subsede do Campeonato Mundial de Futebol (COPA FIFA 2014), surge a "oportunidade" para a ampliação do hall de atrativos ditos turísticos (além do sol e da praia). Nesse contexto, o governo estadual (em consonância com o planejamento do governo municipal) faz uso político, da propaganda e do marketing, promovendo Fortaleza não mais como cidade do semiárido, mas como metrópole moderna e propicia a organização de eventos com desdobramentos internacionais.

Na concepção dos planejadores públicos e privados, o turismo apresentase como uma atividade econômica estratégica para o desenvolvimento econômico do estado. Concomitantemente, e já como desdobramentos, os projetos privados adensam-se nas áreas mais bem servidas de infraestrutura, pré-requisito básico para a efetivação das práticas turísticas de massa no litoral. A engrenagem da elaboração de projetos e da alocação de recursos passa por várias fases e esferas de governo, desde a municipal até a federal.

Assim, o governo do estado do Ceará vem contraindo empréstimos em instituições internacionais com o intuito de finalizar projetos considerados estruturantes: a duplicação da rodovia CE-040 (litoral leste) e da rodovia CE025, num total de 44,5 km, com orçamento de $\mathrm{R} \$ 81,6$ milhões; a construção do Centro de Eventos do Ceará (Fortaleza), com gasto de R $\$ 468,51$ milhões; a construção, ainda em andamento, do Acquário Ceará, também em Fortaleza, estimada inicialmente em R\$250 milhões (Secretaria de Turismo do Ceará Setur, 2013).

Várias obras direcionadas à Copa do mundo foram planejadas, destacandose: o veículo leve sobre trilhos (VLT) Parangaba/Mucuripe (R $\$ 265,5$ milhões, de 
acordo com a Controladoria Geral da União, em 2012); a reforma, a construção e a conclusão do metrô (linhas sul, oeste e leste - linha leste orçadas em R\$ 4,2 bilhões, segundo o Metrofor, 2013); o Terminal portuário de passageiro do Mucuripe (R\$149 milhões - CGU, 2012); a reforma e ampliação do aeroporto de Fortaleza (R\$ 349,8 milhões - CGU, 2012); a construção de corredores exclusivos de ônibus - BRTs (avenidas Dedé Brasil - R \$ 41,6 milhões, Paulino Rocha - R\$ 34,6 milhões e Alberto Craveiro - R\$ 33,7 milhões - CGU, 2012); a Ponte estaiada sobre o Rio Cocó (orçada em R $\$ 259$ milhões - Governo do Ceará, 2013). Destes, apenas o terminal marítimo de passageiros foi concluído.

A análise aqui proposta, inicialmente, partirá da compreensão do papel do turismo como vetor estratégico do planejamento do espaço, desde as políticas públicas até a vinculação metropolitana e regional. Dessa forma, iniciamos com uma discussão teórica sobre a globalização, turismo e o empreendedorismo urbano; em seguida, discute-se a consolidação do turismo pela análise dos fluxos e fixos na metrópole (empreendimentos e circulação de pessoas); por fim, analisaremos as recentes estratégias vinculadas ao turismo de eventos, que se apresenta como possibilidade de ampliação dos fluxos turísticos no Ceará. Utiliza-se, assim, um discurso turístico vinculado à lógica metropolitana, destacando-se a cidade de Fortaleza como o principal espaço gerador e atrativo da dinâmica turística.

\section{GLOBALIZAÇÃO, TURISMO E EMPREENDEDORISMO URBANO}

No século XXI, o capitalismo continua a se desenvolver como um modo de produção material, simultaneamente nacional e internacional, a rigor um processo civilizatório, na qual o turismo e o empreendedorismo urbano tornamse fatores fundamentais. Alguns autores afirmam que o novo século passa por uma diferente etapa da globalização, na qual o sistema de informação, alavancado pela internet e o sistema de marketing, a terceirização dos serviços tornam a noção de mundo diferente do que conhecemos, afirmando, com certo exagero, que o mundo se tornou plano e com isso a competição empresarial é similar em todos os recantos do mundo (FRIEDMAN, 2014).

De maneira geral, a globalização é a internacionalização do capitalismo em sua fase mais avançada (IANNI, 2001; SANTOS, 2011). Dessa forma, as cidades tornam-se centros dessa internacionalização do capital, onde reina o consumismo, o fluxo de finanças e a política do empreendedorismo urbano. Santos (2011) afirma que as empresas hegemônicas produzem o consumidor antes mesmo de produzir os produtos, ou seja, a política agora é feita no mercado, só que esse mercado global não existe como ator, mas como uma ideologia, um símbolo. 
Dessa maneira, a ideologia da gestão urbana das cidades é presidida pelo empreendedorismo urbano ${ }^{1}$. A maior parte dos geógrafos afirma que é um erro considerar a globalização uma força causal com respeito ao desenvolvimento local (HARVEY, 2001), as iniciativas locais, inter-urbanas e interregionais podem alcançar uma escala global.

Portanto, o novo empreendedorismo tem como elemento principal, a noção de "parceria público-privado", em que a iniciativa tradicional local se integra ao uso dos poderes governamentais locais, buscando e atraindo fontes externas de financiamento, e novos investimentos diretos ou novas fontes de emprego.

As mundaças não se restringem à logica da produção. As ações públicas e privadas de turistificação das cidades objetivam o desenvolvimento econômico reproduzindo novas formas do/no espaço urbano. As "cidades" disputam turistas. A princípio, nos Estados Unidos e na Europa, e mais recentemente nos países latino-americanos, surgem projetos de renovação urbana, principalmente em áreas centrais e frentes marítimas que ao longo do tempo passaram por processos de esvaziamento e transformação de uso. Esses projetos demonstram o esforço em inserir a cidade na competição global do turismo e, sob a lógica do mercado, tornando-a dependente dos grandes empreendedores (PASSOS, 2014).

No Brasil, precisamente na década de 1990, o desenvolvimento econômico vinculou-se, também, aos desdobramentos econômicos do turismo. É nessa década que emergiram, do poder público federal, várias ações destinadas a organizar o setor no país e criar condições necessárias à sua expansão (CRUZ, 2005). Percebe-se uma ligação entre os princípios do empreendedorismo urbano e as propostas de turistificação das cidades, principalmente as capitais nordestinas associadas às práticas marítimas modernas, destacando-se a capital do Ceará.

Transformações urbanas desencadeadas a partir da realização de megaeventos esportivos têm como exemplo mais representativo o caso das Olimpíadas de Barcelona (1992), em que as práticas de intervenção e planejamento da cidade seguiram um viés mercadológico e transformaram a sua configuração espacial (VAINER, 2011).

De acordo com Mascarenhas (2008), o caso da cidade de Barcelona tornou-se paradigmático, já que os jogos olímpicos foram utilizados como "ponto inicial" para o desenvolvimento urbano. Nesse caso, "[...] o governo

1 Por empreendedorismo urbano utilizaremos o entendimento de David Harvey (2001), o padrão de conduta na governança urbana que combina poderes estatais (local, metropolitano, regional, nacional ou supranacional), diversas formas organizacionais da sociedade civil (camaras de comércio, sindicatos, igrejas, instituições educacionais e de pesquisa, grupos comunitários, ongs etc e interesses privados, formando coalizões para fomentar ou administrar o desenvolvimento urbano/regional de um tipo ou outro. 
local investiu vultosas quantias e implementou projetos urbanísticos de elevada envergadura, redefinindo centralidades e constituindo um verdadeiro marco na evolução urbana" (MASCARENHAS, 2008, p. 116). As Olimpíadas de Barcelona também foram utilizadas para projeção de uma imagem positiva da cidade, incrementando o turismo e atraindo investimentos externos ${ }^{2}$. $\mathrm{Na}$ visão do urbanista Carlos Vainer (2007, p. 78), talvez esta seja, hoje, uma das ideias mais populares entre os planejadores urbanos: “[...] a cidade é uma mercadoria a ser vendida, num mercado extremamente competitivo, em que outras cidades também estão à venda".

Ao longo dos anos 2000, estudos detalharam os resultados dos programas federais que nortearam os investimentos públicos nos polos turísticos nordestinos (DANTAS et al., 2008). Conclusivamente, as análises indicam o papel relevante das ações e dos investimentos efetuados a partir das versões do Prodetur (I, II e Nacional) para consolidar o espaço litorâneo (e, mais especificamente, o metropolitano) como espaço turistificado. No Ceará, parte do litoral oeste e o litoral leste receberam tais recursos. A estratégia caracterizou-se pela reestruturação do litoral cearense, especialmente direcionado ao oeste, já que esse trecho não apresentava fluxos turísticos consolidados como o litoral leste. Dessa forma, compreender as relações entre o urbano e o turismo é relevante para entendermos a reprodução do espaço turístico e metropolitano.

A atuação do setor público e privado no Ceará, nos últimos quatro anos, reforça os argumentos de um governo que busca na Copa do Mundo de 2014 o seu maior legado: o de vitrine do turismo e do empreendedorismo urbano. Deste modo, partimos da premissa da cidade enquanto produto histórico, assim, projetos de desenvolvimento urbanístico agregam não apenas dimensões tecnológicas/arquitetônicas, mas também os vieses político, social e econômico.

\section{DESDOBRAMENTOS DAS ESTRATÉGIAS PÚBLICAS: INVESTIMENTOS PRIVADOS NA CONSOLIDAÇÃO DO TURISMO METROPOLITANO EM FORTALEZA}

Nas últimas duas décadas, o Ceará recebeu vários investimentos privados, originários principalmente de empreendedores europeus, para a construção de hotéis, pousadas, resorts e complexos turísticos, visando ampliar lucros propiciados

\footnotetext{
O trabalho de Ferran Brunet sobre o modelo de Barcelona retrata o sucesso da força dos objetivos traçados, impactos urbanos e excelência organizacional, as parcerias interinstitucionais e os impactos em larga escala da cidade na infraestrutura urbana. Esses impactos associados ao modelo de marketing territorial foi resultado de um conjunto de parcerias entre os gestores urbanos e a oportunidade dos jogos olímpicos como difusor dessa imagem (BRUNET, 2009)
} 
pelo aumento dos fluxos turísticos no estado, apoiados nas infraestruturas básicas previamente instaladas, além de incentivos estaduais e municipais.

A organização da atividade turística em Fortaleza extrapola os limites citadinos e desempenha um papel metropolitano: nos municípios adjacentes à cidade, instalam-se empreendimentos do tipo resorts e complexos turísticoimobiliários (demandantes de maior área territorial que comumente os lotes urbanos dispõem). A localização se explica por legislações municipais mais flexíveis, pela disponibilidade de grandes glebas a beira-mar e menor preço da terra (se comparado aos cobrados na sede metropolitana).

A série histórica demonstra que a cidade de Fortaleza concentra os empreendimentos turísticos do Ceará e da Região Metropolitana de Fortaleza (RMF): em 2009 eram 199 empreendimentos, e dados de 2012 registram 207 empreendimentos. Em relação aos tipos, é preciso mencionar que há predominância de hotéis de redes nacionais/internacionais e de pousadas, situados em sua maioria na orla marítima dos bairros Meireles e Aldeota situados na capital.

Para o restante do espaço metropolitano, destacam-se também os municípios litorâneos, notadamente Aquiraz, São Gonçalo do Amarante e Caucaia, que concentram 125 empreendimentos, correspondentes a 36\% de todos os localizados na RMF, empreendimentos esses incluídos nos novos tipos com atrativos internos e serviços all incluse. Apesar do município de Cascavel ter sido integrado à RMF apenas em 2009, registra-se também acréscimo significativo em seu número total de empreendimentos turísticos.

O município de Aquiraz - que se destaca pelas localidades conhecidas turisticamente, Porto das Dunas, Prainha, Iguape, Barro Preto -, entre 2009 e 2012, foi incrementado com nove empreendimentos, totalizando 43 em 2012. Hierarquicamente, destaca-se como o segundo município com maior número de empreendimentos da RMF. As figuras 1, 2, 3 e 4 destacam a evolução e a concentração de equipamentos turísticos nos municípios da RMF.

Para o caso de Fortaleza, a aproximação da realização dos eventos esportivos internacionais promoveu desdobramentos em investimentos na construção de empreendimentos urbanos. Desde 2008 não eram construídos equipamentos hoteleiros na cidade, todavia entre 2011 e 2012 foram inaugurados oito empreendimentos. Quanto ao número de leitos, percebe-se que em Fortaleza houve, entre 2005 e 2012, aumento de 1.778 leitos, registrando, em 2012, número igual a 26.419 leitos. 
Figura 1 - Tipos e concentração de empreendimentos turísticos na RMF (2009)

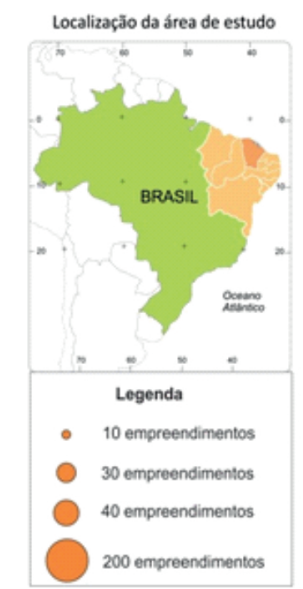

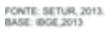

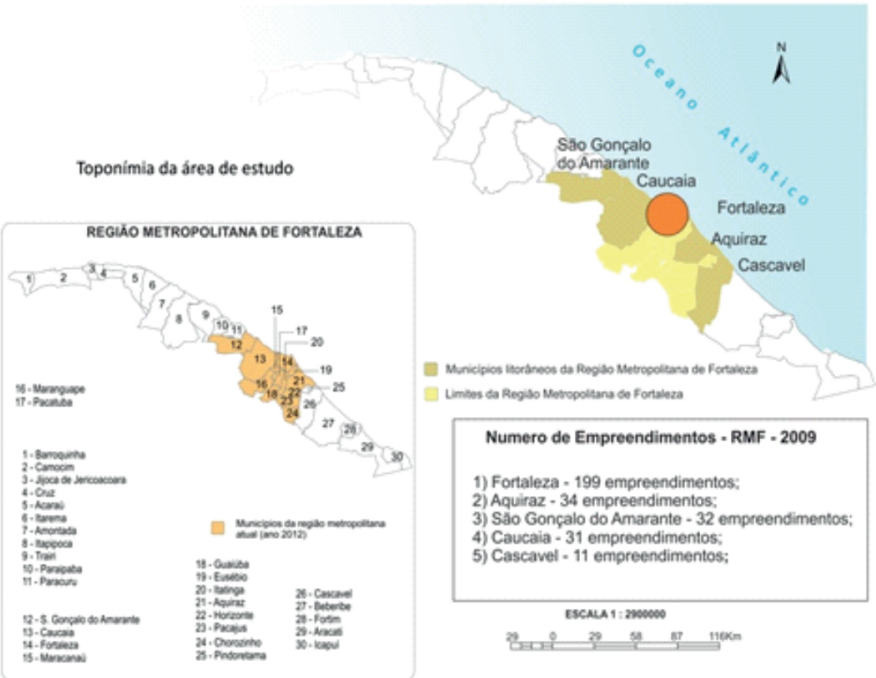

Fonte: SETUR, 2014.

Figura 2 - Tipos e concentração de empreendimentos turísticos na RMF (2010)

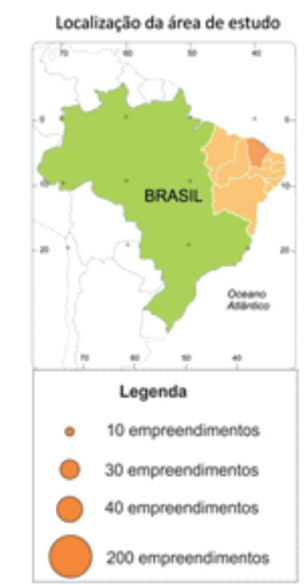

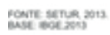

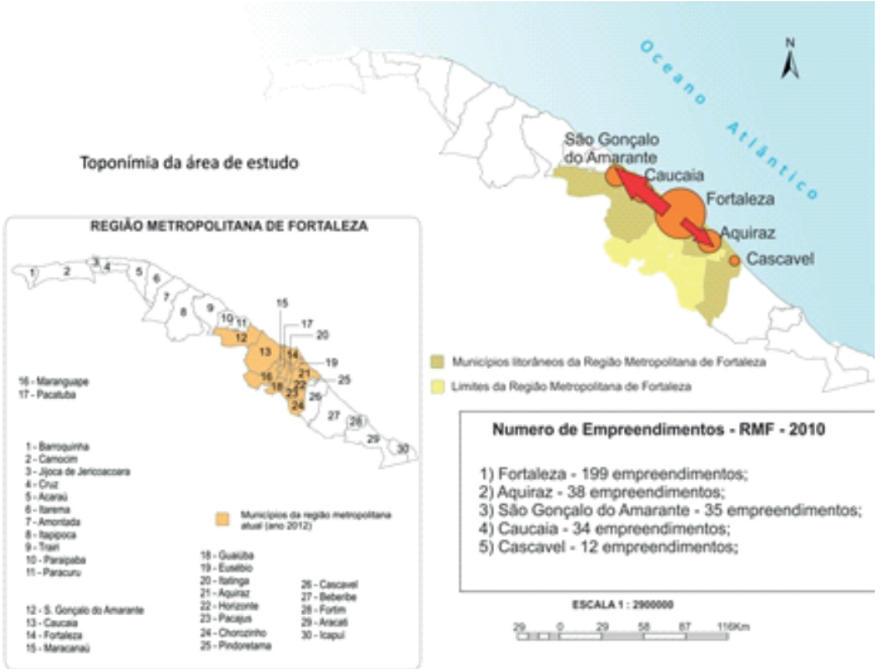

Fonte: SETUR, 2014. 
Figura 3 - Tipos e concentração de empreendimentos turísticos na RMF (2011)

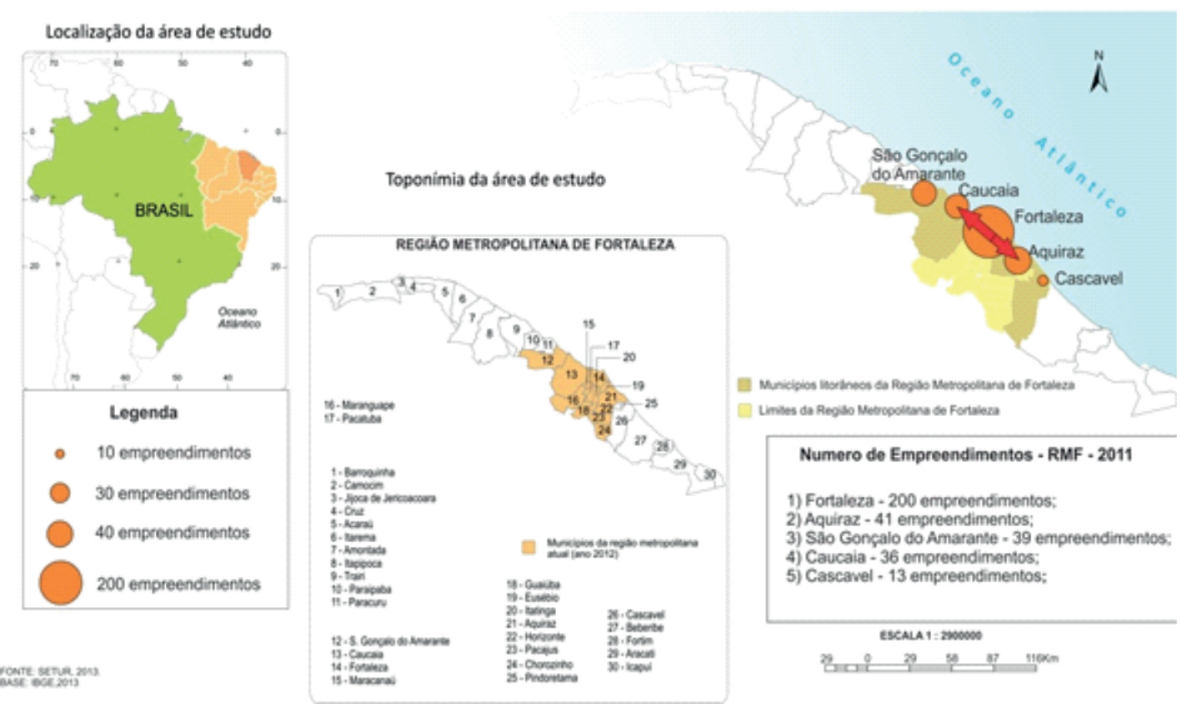

Fonte: SETUR, 2014.

Figura 4 - Tipos e concentração de empreendimentos turísticos na RMF (2012)

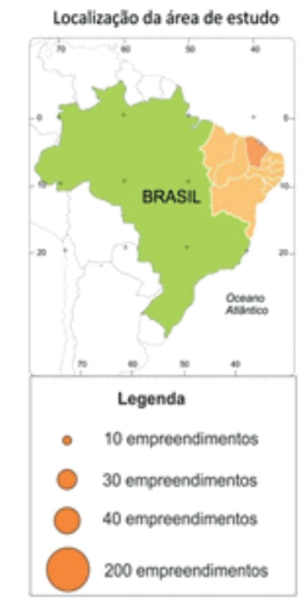

monec sorve sons
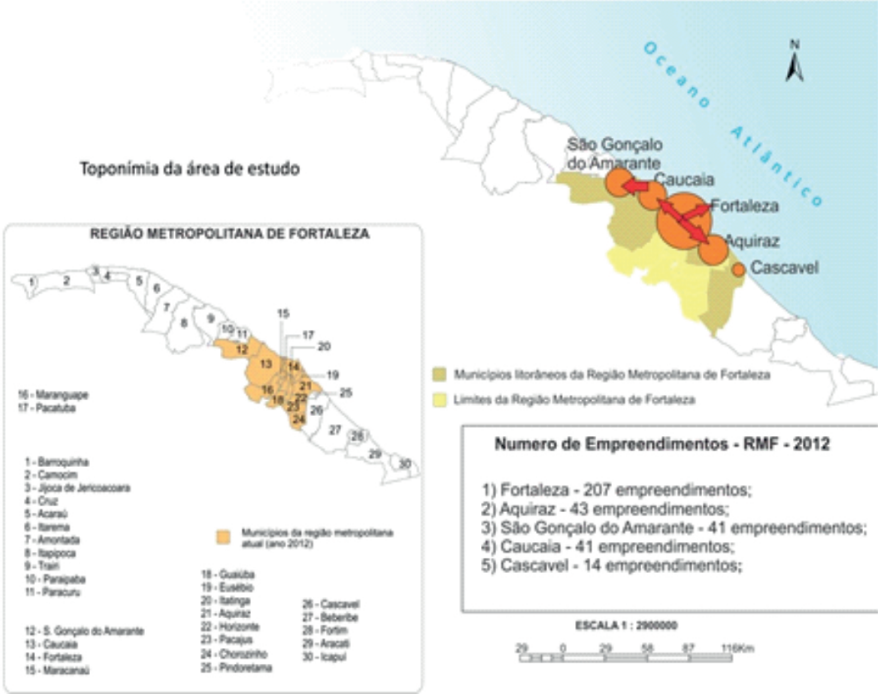

Fonte: SETUR, 2014.

Assim, historicamente e por todas as características de aglomeração de uma capital no contexto brasileiro, Fortaleza se mantém com o maior número de empreendimentos turísticos da RMF. Todavia, o movimento diferencial, tanto em relação a quantitativos como em relação a inovações no padrão tipológico, 
é observado nos demais municípios litorâneos metropolitanos: Aquiraz (com 9 empreendimentos em 3 anos), São Gonçalo do Amarante e Caucaia (com 11 e 10 empreendimentos, respectivamente), e Cascavel (extremo leste da RMF) apresentou uma variação de 3 empreendimentos no mesmo período (tabela 1).

Tabela 1 - Evolução dos empreendimentos turísticos na RMF (2009-2012)

\begin{tabular}{l|c|c|c|c|c|c}
\hline \multicolumn{1}{c|}{ Município } & 2009 & 2010 & 2011 & 2012 & $\begin{array}{c}\text { Período } \\
2009-2012\end{array}$ & Dif. (\%) \\
\hline Fortaleza & 199 & 199 & 200 & 207 & +8 & $+4 \%$ \\
\hline Aquiraz & 34 & 38 & 41 & 43 & +9 & $+26,4 \%$ \\
\hline São Gonçalo do Amarante & 32 & 35 & 39 & 41 & +11 & $+28,12 \%$ \\
\hline Caucaia & 31 & 34 & 36 & 41 & +10 & $+32,2 \%$ \\
\hline Cascavel & 11 & 12 & 12 & 14 & +3 & $+27,7 \%$ \\
\hline TOTAL RMF & 307 & 318 & 328 & 345 & +38 & $+12,4 \%$ \\
\hline
\end{tabular}

Fonte: Setur, 2014.

Apresenta-se, assim, um cenário em que o crescimento dos fixos relacionados à atividade turística é apresentado como sucesso de uma política de turistificação do espaço litorâneo metropolitano, tornando-se, ainda, uma "esperança" para a estratégia de manter a metrópole atrativa aos olhos dos turistas nacionais e de estimular o perfil internacional da atividade. Ou seja, a cidade de Fortaleza e sua franja metropolitana [itorânea] são planejadas para atrair recursos financeiros para consolidar a sua imagem "turística, litorânea e internacional".

\section{NOVAS ESTRATÉGICAS PÚBLICAS DIANTE DOS MEGAEVENTOS: MANUTENÇÃO OU REESTRUTURAÇÃO DE FLUXOS TURÍSTICOS?}

Os investimentos destinados à atividade turística - notadamente de origem estadual e posteriormente federal - visavam, entre outros objetivos, o aumento do fluxo de turistas. A criação da Secretaria de Turísmo do Estado (Setur), ainda na década de 1990, reflete a prioridade do turismo como vetor de desenvolvimento do estado.

Tais ações alavancam os fluxos turísticos do Ceará, principalmente após os anos 1998, com a efetivação da Setur e de sucessivas ações construídas pelo Prodetur/NE I. O Ceará passa de 761.777 turistas ainda em 1995 para quase 3,2 milhões em 2015 e registra um aumento de 420\% em 20 anos, perfazendo um crescimento médio de $20 \%$ ao ano. 
Os fluxos turísticos do Ceará são predominantemente procedentes dos estados brasileiros: tanto em 2009 como em 2014 o número de turistas originários de outras nacionalidades não alcançou mais de $8,5 \%$ do total de visitantes no estado (Quadro 1).

Quadro 1 - Demanda turística via Fortaleza (1995-2014)

\begin{tabular}{|l|r|r|r|r|r|r|r|}
\hline \multicolumn{7}{|c|}{ DEMANDA TURÍSTICA VIA FORTALEZA 1995/2014 } \\
\hline \multirow{2}{*}{ ANOS } & \multicolumn{2}{|c|}{ TOTAL } & \multicolumn{2}{|c|}{ NACIONAL } & \multicolumn{2}{|c|}{ INTERNACIO- } & $\begin{array}{r}\text { PARTICI- } \\
\text { PAÇÃO }\end{array}$ \\
\cline { 2 - 8 } & TURISTAS & \multicolumn{1}{|c|}{ IA } & TURISTAS & IA & TURISTAS & \multicolumn{1}{c|}{ IA } & $(\%)$ \\
\hline 1996 & 773.247 & 100 & 733.038 & 100 & 40.209 & 100 & 5,2 \\
\hline 1997 & 970.000 & 125,1 & 914.710 & 121,8 & 55.290 & 137,5 & 5,7 \\
\hline 1998 & 1.297 .528 & 167,8 & 1.218 .379 & 166,2 & 79.119 & 196,8 & 6,1 \\
\hline 1999 & 1.388 .490 & 179,6 & 1.296 .850 & 176,9 & 91.640 & 227,9 & 6,6 \\
\hline 2000 & 1.507 .914 & 195 & 1.387 .281 & 189,3 & 120.633 & 300 & 8 \\
\hline 2001 & 1.631 .072 & 210,9 & 1.458 .178 & 198,9 & 172.894 & 430 & 10,6 \\
\hline 2002 & 1.629 .122 & 210,7 & 1.446 .927 & 197,4 & 182.495 & 453,9 & 11,2 \\
\hline 2003 & 1.550 .857 & 200,6 & 1.356 .539 & 185,1 & 194.318 & 483,3 & 12,5 \\
\hline 2004 & 1.784 .354 & 230,8 & 1.534 .544 & 209,3 & 249.810 & 621,3 & 14 \\
\hline 2005 & 1.968 .856 & 254,6 & 1.703 .060 & 232,3 & 265.796 & 661 & 13,5 \\
\hline 2006 & 2.062 .493 & 266,7 & 1.794 .369 & 244,8 & 268.124 & 666,8 & 13 \\
\hline 2007 & 2.079 .590 & 268,9 & 1.830 .039 & 249,7 & 249.551 & 620,6 & 12 \\
\hline 2008 & 2.178 .395 & 281,7 & 1.956 .285 & 266,9 & 222.110 & 552,4 & 10,2 \\
\hline 2009 & 2.466 .511 & 319 & 2.256 .858 & 307,9 & 209.653 & 521,4 & 8,5 \\
\hline 2010 & 2.691 .729 & 348,1 & 2.472 .299 & 337,3 & 219.430 & 545,7 & 8,2 \\
\hline 2011 & 2.848 .459 & 368,4 & 2.628 .361 & 358,6 & 220.098 & 547,4 & 7,7 \\
\hline 2012 & 2.995 .021 & 387,3 & 2.761 .412 & 376,6 & 233.618 & 581 & 7,8 \\
\hline 2013 & 3.141 .406 & 406,3 & 2.895 .646 & 395 & 245.760 & 611,2 & 7,8 \\
\hline 2014 & 3.262 .259 & 421,9 & 2.989 .465 & 407,8 & 272.794 & 678,4 & 8,4 \\
\hline
\end{tabular}

$\mathrm{IA}=$ Indice Acumulado à $\mathrm{O}$ índice é baseado no primeiro ano, em comparação com os demais.

Fonte: Setur, 2014.

As transformações no quantitativo dos fluxos turísticos estão relacionadas as intervenções e cenários locais/nacionais e internacionais, produzindo, dessa maneira, efeitos distintos na produção do espaço turistificado. Analisando os fluxos de turistas no Ceará durante o período (1995-2014), verificamos quatro grandes etapas significativas do fluxo turístico cearense. (Figura 5): 
a) 1997-1998: Período de acréscimo de turistas. Devido principalmente à ampliação do Aeroporto Internacional Pinto Martins, realizado até então no Governo Tasso Jereissati, aumentou significativamente o número de passageiros para 2,5 milhões/ano.

b) 2003-2004: Crise internacional e fortalecimento nacional. Devido à crise internacional relacionada aos atentados em Nova York em 2001, a curva do fluxo turístico internacional passou por uma inflexão, apresentando resultados desfavoráveis nos anos posteriores. Contudo, para o contexto brasileiro, após o primeiro mandato do governo Lula, houve crescimento econômico acima do dos anos anteriores, favorecendo e intensificando os fluxos nacionais.

c) 2008-2009: Manutenção de tendência. Período de crise dos EUA e Japão, mas, com a maior estabilidade financeira do Brasil, os fluxos continuaram em crescimento.

d) 2013-2014: Tendência de crescimento. A Copa das Confederações (2013) e o evento da Copa do Mundo (2014) não produziram instantaneamente fluxos consideráveis como se esperava o planejamento governamental. Observa-se, crescimento de 3,8\% de 2013 à 2014 em plena Copa do Mundo, enquanto de 2013 ao ano de 2012, um crescimento de 4,9\%.

Figura 5 - Evolução do número de turistas no Ceará (1995-2014)

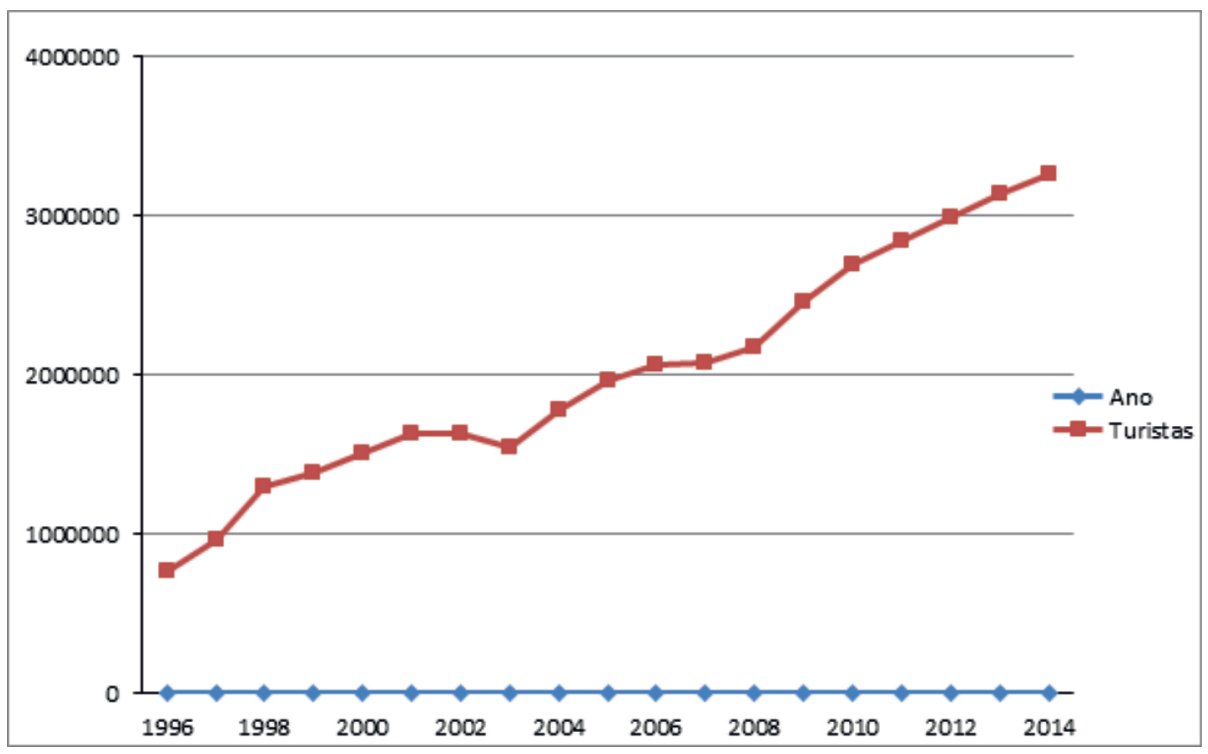

Fonte: SETUR, 2015. 
As estratégias estaduais para incremento nos quantitativos dos fluxos turísticos na RMF passam pela consolidação de infraestrutura urbana. Com a escolha de Fortaleza como subsede da Copa 2014, é produzido um novo conjunto de ações, considerada a segunda etapa de estratégias turísticas no Ceará. Nessa etapa, o discurso levanta as seguintes bandeiras: manutenção e/ou ampliação dos fluxos turísticos; consolidação da imagem da cidade como centro organizador de eventos nacionais/internacionais voltados para os negócios (seminários, congressos e feiras) e entretenimento de massa (shows e competições nacionais).

A priori, mesmo antes da realização da Copa FIFA 2014, o planejamento estatal associa os usos da Arena e o do Centro de Convenções (principais equipamentos já concluídos) como evidências de uma nova etapa das atividades turísticas no estado, ou melhor, na metrópole. A organização local de eventos nacionais e internacionais é ação relevante para a firmação da imagem metropolitana de Fortaleza, diante, inclusive, de outros centros da região Nordeste.

O processo de transformação do estádio Plácido Aderaldo Castelo em arena padrão FIFA é significativo para entender o objetivo dos governos locais em demarcar a eficiência como marca da cidade. Estabeleceu-se o cronograma, e a cada boletim parcial descritivo do andamento das obras alardeava-se o caso cearense como o único que seguia os prazos estabelecidos pelo Comitê Organizador Local da Copa (COL).

A antecipação da data de inauguração transformou-se num marco, à medida que se propagou nacional e internacionalmente a Arena da cidade de Fortaleza como a primeira a ser concluída em dezembro de 2012. Vale mencionar que nesse mesmo ano, no mês de agosto, fora inaugurado em Fortaleza o Centro de Eventos do Ceará (CEC), classificado pela publicidade estatal como o mais moderno da América Latina e o segundo maior localizado em território brasileiro.

Logo após a inauguração do CEC, o governo estadual divulgou, através do Instituto de Pesquisa e Estratégia Econômica do Ceará (Ipece), o relatório técnico indicativo dos impactos econômicos do empreendimento. Para os técnicos, a operacionalização anual gerará um incremento de 0,9\% do PIB estadual. O estudo faz relação direta entre os dividendos originários da realização de shows, feiras, congressos, convenções e os gastos dos visitantes na chamada cadeia de produtos e serviços turísticos. Dessa maneira, a propaganda pública divulgou que os gastos desses novos visitantes farão "uma injeção de R \$ 541,2 milhões na economia estadual". De fato, nota-se um aumento dos fluxos turísticos em todas as modalidades na cidade, tendo a modalidade turística de negócios e eventos um acréscimo contínuo (Tabela 2). 
Tabela 2 - Demanda turística via Fortaleza

\begin{tabular}{l|r|r|r|r}
\hline \multicolumn{1}{c|}{ Demanda } & \multicolumn{1}{c|}{2009} & \multicolumn{1}{c|}{2010} & \multicolumn{1}{c}{2011} & \multicolumn{1}{c}{2012} \\
\hline Passeio & 1.257 .921 & 1.275 .880 & 1.315 .988 & 1.411 .255 \\
\hline Visita Parente/ amigo & 485.903 & 519.504 & 521.268 & 557.074 \\
\hline Negócios/Trabalho & 446.438 & 570.647 & 623.813 & 649.920 \\
\hline Congresso/eventos & 180.055 & 218.030 & 262.058 & 311.482 \\
\hline Outros & 96.194 & 107.669 & 125.332 & 65.292 \\
\hline TOTAL & 2.466 .511 & 2.691 .729 & 2.848 .459 & 2.995 .023 \\
\hline
\end{tabular}

Fonte: Setur, 2013 (organizada pelos autores).

O governo estadual mantém os investimentos em infraestrutura no litoral para a manutenção do Ceará como um destino com vantagem competitiva em relação aos demais estados da região Nordeste. Simultaneamente, os investimentos na Arena Castelão e no CEC representam tentativas de inserção da capital cearense na "disputa" não mais estritamente regional, estando, todavia, em patamar bem inferior aos dois principais polos metropolitanos do país. A estratégia mencionada alinha-se com uma dinâmica recente, mas preexistente à inauguração dos fixos destacados (Tabela 2). A empresa brasileira Brasilturis salientou que a capital cearense se destacou nacionalmente na realização de eventos internacionais durante o ano de 2012.

\section{NOVAS ESTRATÉGIAS PARA O EMPREENDEDORISMO URBANO DE EVENTOS EM FORTALEZA?}

Para vislumbrar as ações do governo do Estado do Ceará com a iniciativa privada deve-se refletir sobre o papel da constituição da cultura de eventos para a economia das cidades. Muitas das inovações e dos investimentos para tornar certos núcleos urbanos mais atraentes como centros culturais, de eventos e de consumo foram rapidamente imitadas em outros lugares, tornando efêmera qualquer vantagem competitiva num conjunto de cidades (HARVEY, 2005). Harvey chama atenção que a ênfase no turismo, na produção e no consumo de espetáculos, na promoção de eventos efêmeros num determinado palco, mostra todos os sinais de ser o remédio predileto para economias enfermas.

As indicações do chamado "legado" da copa do mundo em Fortaleza revela estratégias de utilização da Arena Castelão, do CEC, Casas de shows e a rede hoteleira para promoção de eventos e grandes shows internacionais para o turismo na cidade. A cidade passa a ter como marketing a utilização desses 
grandes shows internacionais e da proposta de atração de grandes eventos para promoção de sua imagem. Em artigo, a Izabela Teobaldo (2010) alerta que os novos espaços urbanos promovidos internacionalmente como roteiros globais são cada vez mais comum e produzidos através de um discurso único: promessas aos cidadãos da recuperação de uma suposta vida local, dotando os espaços públicos de melhorias da infraestrutura, através de projetos envolvendo alta tecnologia.

Deve-se ter cautela ao comparar o turismo de grandes cidades globais com cidades de países em desenvolvimento e com grandes lacunas de infraestrutura urbana, no entanto, pode-se observar tendências de política urbana de promoção da cidade que revelam mudanças ocasionadas pela perspectiva de eventos em escala global. Os espaços transformados através das políticas de requalificação urbana voltatam-se para as classes médias e abastadas, com serviços de lazer e cultura, bares, restaurantes, galerias de arte, lojas e aparatos de entretenimento.

Em levantamento do número de shows internacionais na cidade de Fortaleza, nota-se que a Arena Castelão e o CEC são acionados como palco de eventos internacionais. No caso desse tipo de evento, não se vislumbra o fortalecimento do fluxo turístico nacional, visto que os shows não são exclusivos nem no país nem mesmo na região Nordeste. Outro indicador é o conjunto de espectadores, cuja origem é da capital e dos demais municípios do próprio estado.

Quadro 2 - Apresentações artísticas internacionais em Fortaleza (2011 a 2016)

\begin{tabular}{|l|l|r|}
\hline \multicolumn{1}{|c|}{ Artista } & \multicolumn{1}{c|}{ Local } & Ano \\
\hline Jack Johnson (E.U.A) & Marina Park & 2011 \\
\hline Gorillaz e Snoop Dogg (E.U.A) & Mucuripe Club & 2011 \\
\hline Jason Mraz (E.U.A) & Clube SiaráHall & 2011 \\
\hline Sublime With Rome (E.U.A) & Barraca Biruta & 2011 \\
\hline Deep Purple (ING) & Barraca Biruta & 2011 \\
\hline Black Eyed Peas (EUA) & Marina Park Hotel & 2011 \\
\hline 50 Cent (EUA) & Clube SiaráHall & 2012 \\
\hline Graundation (E.U.A) & Club Armazém & 2012 \\
\hline Air Supply (AUS) & Clube SiaráHall & 2012 \\
\hline Colin Hay (AUS) & Clube SiaráHall & 2012 \\
\hline Jennyfer Lopez (EUA) & Centro de Eventos & 2012 \\
\hline Plácido Domingo (Esp.) & Centro de Eventos & 2012 \\
\hline Evanescence (EUA) & Marina Park & 2013 \\
\hline Paul McCartney (Ing.) & Arena Castelão & 2013 \\
\hline Beyoncé (EUA) & Arena Castelão & \\
\cline { 1 - 3 }
\end{tabular}




\begin{tabular}{|l|l|r|}
\hline DJ. David Guetta (FRA) & Centro de Eventos & 2014 \\
\hline Elton John (ING.) & Arena Castelão & 2014 \\
\hline Guns N'Roses (E.U.A) & Centro de Eventos & 2014 \\
\hline Dream Theater (E.U.A) & Clube SiaráHall & 2014 \\
\hline Soja (E.U.A) & Centro de Eventos & 2014 \\
\hline Midnite e Dezaire (Caribe) & Barraca Biruta & 2014 \\
\hline $\begin{array}{l}\text { Julian Marley e the Wailers } \\
\text { (JAM) }\end{array}$ & Barraca Santa Praia & 2015 \\
\hline Sonata Arctica (FIN) & Club Armazém & 2015 \\
\hline Banda A-HA (NOR) & Aquaville Resort & 2015 \\
\hline Blind Guardian (ALE) & Clube SiaráHall & 2015 \\
\hline Iron Maden (ING) & Arena Castelão & 2016 \\
\hline Maroon 5 (E.U.A) & Marina Park Hotel & 2016 \\
\hline
\end{tabular}

Fonte: Governo do Ceará e Jornal Tribuna Ceará, 2016 (organizado pelos autores).

Outras ações do Governo do Estado do Ceará com entidades públicas e privadas para a promoção da capital Fortaleza foram delineadas nos últimos anos. Pode-se citar a realização da VI Conferência de Cúpula dos Brics, realizada no CEC em Fortaleza no ano de 2014, com os presidentes da China, Rússia, Indía, África do Sul e Brasil. Um fórum empresarial abriu o encontro com 700 empresários das 602 maiores empresas dos cinco países. Forão assinados nove atos de cooperação, entre acordos comerciais, intercâmbio de informações e cooperações nas áreas de tecnologia, defesa e energia (Jornal Globo, 2014).

O Governo do Ceará estabelece um cronograma de finalização de um gigante aquário marinho na praia de Iracema, projeto de requalificação de parte do litoral que se justifica pela capacidade de atrair turistas nacionais e internacionais e promover um roteiro de eventos para a pesquisa de animais marinhos.

A discussão sobre o denominado legado pós-copa vem minguando ao longo do tempo, restando como argumento, já bastante contestado, a difusão internacional de imagens positivas sobre a cidade e o estado.

\section{CONSIDERAÇÕES FINAIS}

Entre 2009 e 2016, as metrópoles brasileiras passam por intervenções urbanas associadas à Copa do Mundo. Ratifica-se a importância do poder público na produção do espaço. A adequação da cidade às principais demandas do evento tem funcionado como argumento para acelerar a implantação de obras e captar recursos para projetos que, em muitos casos, já estavam previstos, 
independentemente da realização do megaevento esportivo. Todavia, as políticas públicas em função do turismo proporcionam mudanças pontuais na organização territorial das cidades, geralmente alicerçadas na justificativa de atrair e consolidar o fluxo turístico pós-copa.

Durante o anúncio de Fortaleza como cidade-sede da Copa do Mundo de 2014, o governo do estado preocupou-se em associar a imagem turística de Fortaleza (sol, praia, e belezas naturais) com a modernidade dos serviços e dos equipamentos urbanos. Incorporou-se estratégia de organização do "turismo de negócios e eventos" na capital cearense. Esse segmento faz parte de um novo/velho projeto fomenta redefinições urbanas e metropolitanas. Remoções de habitantes, complementação da malha ferroviária nos municípios da RMF, construção de pontes, terminal marítimo de passageiros, centro de convenção e modernização dos estádios de futebol fazem parte desse momento na cidade.

A cidade de Fortaleza mantém na concorrência regional frente as cidades de Salvador e Recife. Tal consequência percebe-se pelo crescimento econômico de Fortaleza nos últimos anos. Segundo o IBGE (2015) a capital cearense é a mais rica do Nordeste brasileiro, com PIB de R $\$ 42,6$ bilhões, ultrapassando as demais capitais. Em termos estaduais, as ações vinculadas ao turismo e ao volume de investimentos públicos e privados derivados propiciam a consolidação do processo iniciado no século XX: o aumento da concentração de riquezas na RMF.

\section{REFERÊNCIAS}

BRUNET, F. The economy of the Barcelona Olympic Games. In: Gavin Poynter and Iain Mac Rury: Olympic Cities: 2012 and the Remaking of London. 1ed. Londres, CRV. 2009. p 98-115.

COSTA, M.C.L. A produção do espaço urbano em Fortaleza. Revista da sociedade cearense de Geografia e História, v. 2007/2, p 11-21, 2008.

CRUZ, R. C. A. da. Políticas Públicas de Turismo no Brasil: território usado, território neglicenciado. Geosul (UFSC), Florianópolis, SC, V.20, n.40, p. 27-43, 2005

DANTAS. E. W. C; PEREIRA, A.Q; PANIZA, A. Urbanização litorânea e vilegiatura maritíma nas metrópoles nordestinas brasileiras. Cidades (Presidente Prudente), V.5, p. 14-34, 2008.

FRIEDMAN, T. O Mundo é plano: o mundo globalizado no século XXI. 3 ed. São Paulo: Companhia das letras, 2014. 
HARVEY, D. El derecho a la ciudad. Madrid: Akal, n. 53, 2008, pp. 23-40.

A Produção Capitalista do Espaço. São Paulo: Annablume, 2005

IANNI, O. A Sociedade Global - 9 ed. Rio de Janeiro: Civilização Brasileira, 2001.

IBGE - Instituto Brasileiro de Geografia e Estatística. Dados sobre as regiões metropolitanas brasileiras, 2013.

PIB dos Estados Brasileiros, 2015.

JORNAL O GLOBO. Reunião dos BRICS acontece em Fortaleza, 2014. Disponível em: www.g1.globo.com/globonews/reuniãobrics. Acesso em: 22 de Março de 2016.

MASCARENHAS, G. O ideário urbanístico em torno do olimpismo. Barcelona (1992) e Rio de Janeiro (2007): os limites de uma apropriação. In: Elson Manoel Pereira (Org). Planejamento Urbano no Brasil: conceitos, diálogos e práticas. Chapecó: Argos, 2008.

PASSOS, F.D.R.L. O espetáculo dos espaços públicos: vivências e expressões culturais na zona portuária do Rio de Janeiro. Revista Brasileira de Estudos Urbanos e Regionais. V.16, N.2, p. 81-96/ nov. de 2014.

PLANO PLURIANUAL (2012-2015). Economia para uma vida melhor. Disponível em: <www.transparencia.ce.gov.br>. Acesso em 15 out. 2013.

TEOBALDO, I.N.C. A cidade espetáculo. Sociologia: Revista do Departamento de Sociologia da FLUP. Vol. XX, p. 137-148, 2010.

SANTOS, M. Por uma outra globalização: do pensamento único à consciência universal. 11ªed. Rio de Janeiro, RJ: Record, 2011.

SETUR. Setur apresenta agenda 2013 de promoção turística. Disponível em: <www.centrodeeventos.ce.gov.br>. Acesso em: 22 fev. 2013.

Dados turísticos do Ceará, 2014.

Dados turísticos do Ceará, 2015.

VAINER, C. B. Planejamento territorial e Projeto Nacional: os desafios da fragmentação. Revista Brasileira de Estudos Urbanos e Regionais. v.9. p. 9-23, 2007. 
Pátria, Empresa e Mercadoria: Notas sobre a estratégia discursiva do planejamento estratégico urbano. In: ARANTES, O (Org.). A Cidade do Pensamento Único: desmanchando consensos. Petrópolis, RJ: Editora Vozes, 2011, p. 75-103. 